\title{
Association between Portal Vein Thrombosis and Survival in Non-Liver-Transplant Patients with Liver Cirrhosis: A Systematic Review of the Literature
}

\author{
Xingshun Qi, ${ }^{1,2}$ Junna Dai, ${ }^{1}$ Man Yang, ${ }^{2,3}$ Weirong Ren, ${ }^{2,4}$ Jia Jia,, $^{2,5}$ and Xiaozhong Guo ${ }^{1}$ \\ ${ }^{1}$ Department of Gastroenterology, General Hospital of Shenyang Military Area, Shenyang 110840, China \\ ${ }^{2}$ Xijing Hospital of Digestive Diseases, Fourth Military Medical University, Xian 710032, China \\ ${ }^{3}$ Department of Gastroenterology, Songgang People's Hospital, Shenzhen 518105, China \\ ${ }^{4}$ Department of Digestive Diseases, Sanmenxia Central Hospital, Henan University of Science and Technology, Xiaoshan Road, \\ Sanmenxia 472000, China \\ ${ }^{5}$ Department of Emergency, Shaanxi Provincial People's Hospital, Xian 710068, China
}

Correspondence should be addressed to Xiaozhong Guo; guo_xiao_zhong@126.com

Received 30 September 2014; Accepted 10 February 2015

Academic Editor: Fabio Farinati

Copyright ( $\odot 2015$ Xingshun Qi et al. This is an open access article distributed under the Creative Commons Attribution License, which permits unrestricted use, distribution, and reproduction in any medium, provided the original work is properly cited.

A systematic review of the literature was performed to analyze the association between portal vein thrombosis (PVT) and survival in non-liver-transplant patients with liver cirrhosis. PubMed, EMBASE, and Cochrane Library databases were searched for all relevant papers which evaluated the prognostic value of PVT in predicting the survival of liver cirrhosis. Meta-analyses were not conducted because the ways of data expression and lengths of follow-up were heterogeneous among studies. Overall, 13 papers were included. The 5-day, 6-week, and 1-year mortality were investigated in 1,3, and 1 studies, respectively; and all of them were not significantly different between cirrhotic patient with and without PVT. By comparison, the 3-year mortality was reported in 1 study; and it was significantly increased by the presence of PVT. The overall mortality was analyzed in 5 studies; and the association with overall mortality and PVT was significant in 4 studies, but not in another one. However, as for the cirrhotic patients undergoing surgical or interventional shunts, the overall mortality was not significantly associated with the presence of PVT in 4 studies. In conclusion, the presence of PVT might be associated with the long-term mortality in non-liver-transplant patients with liver cirrhosis, but not with the short-term mortality.

\section{Introduction}

Liver cirrhosis is the end stage of chronic liver diseases resulting in the life-threatening complications $[1,2]$. According to the Global Disease Burden Study, it is the 12th cause of death, the 17th cause of years of life lost, and the 23rd cause of disability-adjusted life year in the world [3, 4]. The total number of global deaths attributed to liver cirrhosis is increased from 777,800 (95\% uncertainty interval: 663,100-867,900) in 1990 to 1030,800 (95\% uncertainty interval: 868,800 $1160,500)$ in 2010 [3]. The total number of global disabilityadjusted life years due to liver cirrhosis is also increased from 24,327,000 (95\% uncertainty interval: 20,693,000$27,179,000$ ) in 1990 to $31,027,000$ (95\% uncertainty interval:
$25,965,000-34,645,000)$ in 2010 [4]. The natural history of liver cirrhosis is largely influenced by the occurrence of variceal bleeding, ascites, and infection [5-8]. Child-Pugh score, Model for the End-Stage Liver Disease (MELD) score, and their components (i.e., bilirubin, albumin, prothrombin time or international normalized ratio, creatinine, encephalopathy, and ascites) are considered as the major predictors for the survival of liver cirrhosis [5,9]. Recent evidence suggests the potential relationship of the survival with the occurrence of portal vein thrombosis (PVT) in liver cirrhosis [10]. However, the conclusions are inconsistent among studies yet. Herein, we have systematically analyzed the literatures regarding the association of PVT with the short- and 
long-term survival in non-liver-transplant patients with liver cirrhosis.

\section{Methods}

2.1. Search Strategy and Study Selection. All papers regarding PVT had been retrieved via the PubMed, EMBASE, and Cochrane Library databases [11]. Among them, the clinical studies with more than 10 patients were identified [12]. The studies that evaluated the association between PVT and survival/death in liver cirrhosis were further identified. The exclusion criteria were as follows: (1) only malignant patients with PVT were enrolled; (2) PVT developed after surgery or interventional treatments; (3) PVT developed in noncirrhotic patients; (4) only LT recipients with PVT were enrolled; (5) no control group was included (i.e., patients without PVT); (6) the survival was not compared between case and control groups; and (7) no separate data regarding PVT was extracted. Notably, the association of PVT with the survival of LT recipients was evaluated in another meta-analysis study. Therefore, the papers including only LT recipients with PVT were excluded from the present systematic review.

2.2. Data Extraction. The following data were extracted: first author, publication year, study design, enrollment period, target population, treatment modalities, total number of observed patients, and number/percentage of patients with PVT. Additionally, we collected the data regarding the mortality and/or survival rate in cirrhotic patients with and without PVT. If the original data were not reported, the odds ratios (ORs) with 95\% confidence interval (CI), hazard ratios (HRs) with 95\% CI, or $P$ values were collected to express the difference in the mortality and/or survival rate between the two groups. Data were not synthesized because they were expressed in different ways.

2.3. Grade of Evidence. The evidence was classified into high and low grade. The evidence was of high grade, if any one of the 2 following points was met: (1) a multivariate analysis was performed to explore the statistically significant difference; (2) if only a univariate analysis was performed, the baseline Child-Pugh class or MELD score should be matched between patients with and without PVT. Otherwise, the evidence was of low grade.

\section{Results}

3.1. Characteristics of Included Studies. Initially, 10936 papers regarding PVT were identified. Among them, 13 papers were eligible for this systematic review [13-25] (Figure 1). The characteristics of included studies were summarized in Table 1. According to the regions, 4 studies were performed in China Taiwan, 3 studies in Italy, 2 studies in USA, 1 study in Canada, 1 study in France, 1 study in Portugal, and 1 study in UK. According to the enrollment periods, 3 studies were launched before 1990 [21, 23, 24], 3 studies between 1990 and $2000[16,22,25]$, and 6 studies after $2000[13-15,17,19,20]$. The information regarding the enrollment periods was not available in 1 study [18]. According to the publication forms,

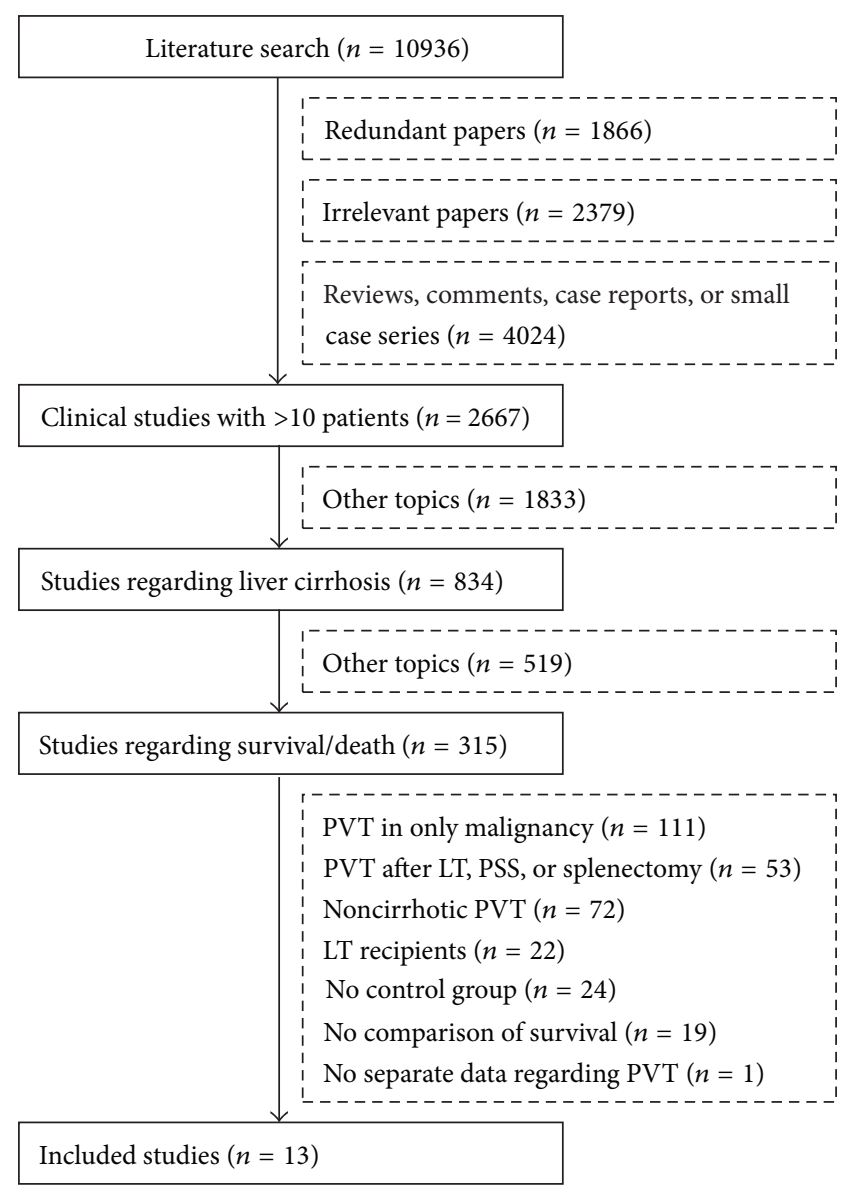

Figure 1: Flowchart of study selection.

3 studies were published in abstracts, and 10 studies in fulltexts. Hepatocellular carcinoma was excluded in 4 studies $[14,17,18,22]$, but not in 6 studies $[13,15,16,19-21,25]$. The information regarding the exclusion of hepatocellular carcinoma was not available in 3 studies $[21,23,24]$. The prevalence of PVT in liver cirrhosis was $7 \%-25 \%$.

Data were expressed in different ways (Table 2). Multivariate analyses were performed in 7 studies $[13-16,18,19,25]$, and only univariate analyses were performed in 6 studies $[17,20-24]$. Of these studies without multivariate analyses, 2 had similar proportions of Child-Pugh classes between patients with and without PVT [17, 22], 2 had significantly different proportions of Child-Pugh classes between the two groups [21, 23], and 2 did not clearly report any relevant information $[20,24]$. Thus, 9 studies were considered to have relatively high-grade evidence.

3.2. 5-Day Mortality. Amitrano and colleagues found that the proportion of PVT was not significantly different between cirrhotic patients who died within 5 days after acute variceal bleeding and those who did not (5/27 versus $27 / 158, P=$ $0.323)[13]$

3.3. 6-Week Mortality. Chen and colleagues reported that PVT was significantly associated with an increased 6-week 


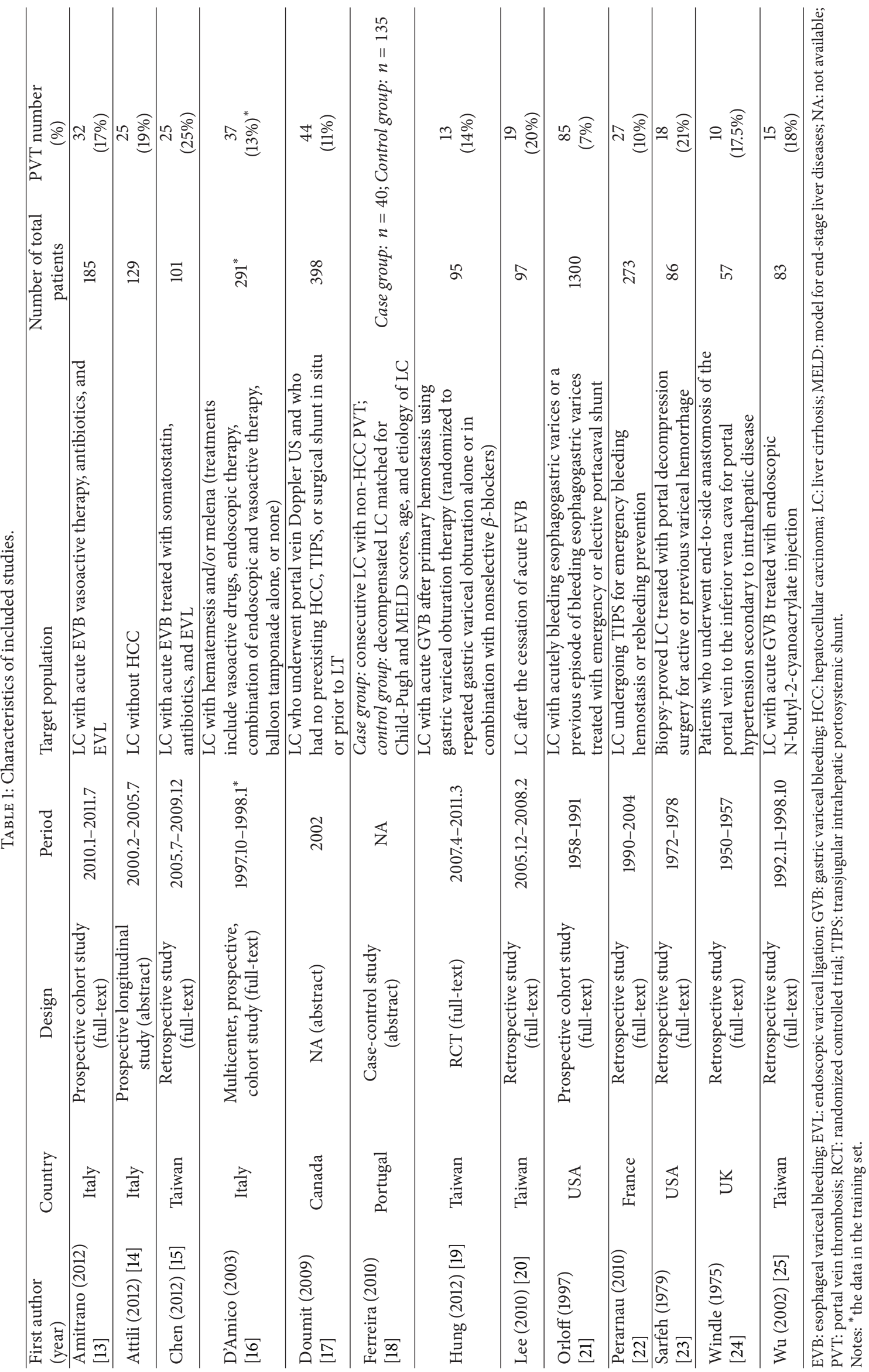


TABLE 2: An overview of survival data expression.

\begin{tabular}{|c|c|c|c|c|c|c|c|c|}
\hline \multirow[b]{2}{*}{ Author (year) } & \multicolumn{8}{|c|}{ Data expression } \\
\hline & $\begin{array}{c}\text { Number } \\
\text { and/or } \\
\text { percentage of } \\
\text { death events }\end{array}$ & Survival time & $\begin{array}{c}\text { Kaplan-Meier } \\
\text { curve }\end{array}$ & $\begin{array}{c}\text { Log-rank } \\
\text { test }\end{array}$ & $\begin{array}{l}\text { Univariate } \\
\text { logistic } \\
\text { regression } \\
\text { analysis }\end{array}$ & $\begin{array}{c}\text { Multivariate } \\
\text { logistic } \\
\text { regression } \\
\text { analysis }\end{array}$ & $\begin{array}{l}\text { Univariate } \\
\text { Cox } \\
\text { regression } \\
\text { analysis }\end{array}$ & $\begin{array}{l}\text { Multivariate } \\
\text { Cox } \\
\text { regression } \\
\text { analysis }\end{array}$ \\
\hline $\begin{array}{l}\text { Amitrano } \\
(2012)[13]\end{array}$ & $\sqrt{ }$ & $x$ & $x$ & $x$ & $\sqrt{ }$ & $\sqrt{ }$ & $x$ & $x$ \\
\hline $\begin{array}{l}\text { Attili (2012) } \\
\text { [14] }\end{array}$ & $\sqrt{ }$ & $x$ & $\sqrt{ }$ & $\sqrt{ }$ & $\times$ & $x$ & $x$ & $x$ \\
\hline $\begin{array}{l}\text { Chen (2012) } \\
\text { [15] }\end{array}$ & $x$ & $x$ & $x$ & $x$ & $\times$ & $x$ & $\sqrt{ }$ & $\sqrt{ }$ \\
\hline $\begin{array}{l}\text { D'Amico } \\
(2003)[16]\end{array}$ & $x$ & $x$ & $x$ & $x$ & $\sqrt{ }$ & $\sqrt{ }$ & $\times$ & $x$ \\
\hline $\begin{array}{l}\text { Doumit } \\
(2009) \text { [17] }\end{array}$ & $\sqrt{ }$ & $x$ & $x$ & $x$ & $x$ & $x$ & $\times$ & $x$ \\
\hline $\begin{array}{l}\text { Ferreira (2010) } \\
{[18]}\end{array}$ & $x$ & $x$ & $x$ & $\sqrt{ }$ & $\sqrt{ }$ & $\sqrt{ }$ & $\times$ & $x$ \\
\hline $\begin{array}{l}\text { Hung (2012) } \\
{[19]}\end{array}$ & $x$ & $\times$ & $x$ & $x$ & $x$ & $x$ & $\sqrt{ }$ & $\sqrt{ }$ \\
\hline $\begin{array}{l}\text { Lee (2010) } \\
{[20]}\end{array}$ & $\sqrt{ }$ & $\times$ & $x$ & $x$ & $\times$ & $x$ & $\times$ & $\times$ \\
\hline $\begin{array}{l}\text { Orloff (1997) } \\
\text { [21] }\end{array}$ & $\sqrt{ }$ & $x$ & $\sqrt{ }$ & $x$ & $\times$ & $x$ & $x$ & $x$ \\
\hline $\begin{array}{l}\text { Perarnau } \\
(2010)[22]\end{array}$ & $\sqrt{ }$ & $\sqrt{ }$ & $\sqrt{ }$ & $\sqrt{ }$ & $x$ & $x$ & $x$ & $x$ \\
\hline $\begin{array}{l}\text { Sarfeh (1979) } \\
\text { [23] }\end{array}$ & $\sqrt{ }$ & $x$ & $\times$ & $x$ & $x$ & $x$ & $\times$ & $x$ \\
\hline $\begin{array}{l}\text { Windle (1975) } \\
\text { [24] }\end{array}$ & $\sqrt{ }$ & $x$ & $x$ & $x$ & $x$ & $x$ & $x$ & $x$ \\
\hline $\begin{array}{l}\mathrm{Wu}(2002) \\
{[25]}\end{array}$ & $\times$ & $x$ & $x$ & $x$ & $x$ & $x$ & $\sqrt{ }$ & $\sqrt{ }$ \\
\hline
\end{tabular}

mortality in the univariate Cox regression analysis $(\mathrm{HR}=3.19$, 95\% CI $=1.59-6.41, P=0.001$ ) [15]. But it was not identified as the independent predictor for the 6-week mortality in the multivariate Cox regression analysis.

D'Amico and colleagues did not find PVT as a significant predicator for the 6-week mortality in the multivariate logistic regression analysis [16].

Lee and colleagues showed that the proportion of PVT was not significantly different between cirrhotic patients who died within 6 weeks after the cessation of initial esophageal variceal bleeding than in those who did not $(40 \%$ [4/10] versus $17.2 \%$ [15/87], $P=0.102$ ) [20].

3.4. 1-Year Mortality. Ferreira and colleagues found that the 1-year mortality was not significantly different between cirrhotic patients with and without PVT (the data was not shown) [18].

3.5. 3-Year Mortality. Ferreira and colleagues found that the 3-year mortality was significantly associated with PVT in cirrhotic patients $(P=0.001)$ [18]. The prognostic significance of PVT for the 3-year mortality was confirmed in the multivariate logistic regression analysis $(\mathrm{OR}=6,95 \% \mathrm{CI}=$ 2-18).
3.6. Overall Mortality. In a prospective longitudinal study by Attili and colleagues, the overall mortality was significantly higher in patients who developed PVT during follow-up than in those who did not $(60 \%$ [15/25] versus 9.6\% [10/104]) [14]. In the Kaplan-Meier curve, the cumulative survival rate was significantly lower in patients with incident PVT than in those without $(P<0.00001$, by log-rank test). The prognostic significance of incident PVT was also confirmed in the multivariate Cox regression analysis.

In a case-control study by Ferreira et al., the Kaplan-Meier curve demonstrated a significantly poorer long-term survival in PVT patients $(P=0.034)[18]$. The association between PVT and mortality was significant in patients with ChildPugh classes A and B, but not in those with Child-Pugh class C.

In a randomized controlled trial by Hung and colleagues, the univariate Cox regression analysis demonstrated that PVT was significantly associated with a poorer overall survival in cirrhotic patients with gastric variceal bleeding undergoing the secondary prevention $(\mathrm{HR}=6.024,95 \% \mathrm{CI}=$ 2.770-13.158, and $P<0.001$ ) [19]. In the multivariate Cox regression analysis, $\mathrm{PVT}$ remained the independent predictor for the overall survival $(\mathrm{HR}=3.390,95 \% \mathrm{CI}=1.499-7.692$, and $P=0.003$ ). 
In a retrospective study by $\mathrm{Wu}$ and colleagues, the univariate Cox regression analysis demonstrated that PVT was significantly associated with the survival in cirrhotic patients with gastric variceal bleeding after endoscopic therapy $(\mathrm{HR}=$ $12.6,95 \% \mathrm{CI}=5.93-26.72$, and $P<0.01)$ [25]. The statistical significance was confirmed in the multivariate Cox regression analysis $(\mathrm{HR}=6.99,95 \% \mathrm{CI}=2.42-20.16$, and $P<0.01)$.

Only one study by Doumit and colleagues found a similar incidence of death between cirrhotic patients with and without PVT (16\% versus 21\%) [17].

\subsection{Mortality after Surgical or Interventional Portosystemic} Shunt. In a study by Windle and Peacock, the overall mortality after end-to-side anastomosis of the portal vein to the inferior vena cava was not significantly different between cirrhotic patients with and without PVT (7/10 [70\%] versus 25/47 [53\%], $P=0.138$, by Chi-square test) [24].

In a study by Sarfeh, the overall mortality after portal decompressive procedures, such as portocaval or mesocaval shunt, was not significantly different between patients with PVT and patent portal veins (10/18 [56\%] versus 26/68 [38\%], $P=0.185$, by Chi-square test) [23].

In a study by Orloff and colleagues, the Kaplan-Meier curve demonstrated a similar survival rate between patients with and without PVT after emergency (30 days: 69\% versus $73 \%, 1$ year: $66 \%$ versus $65 \%$, 5 years: $65 \%$ versus $61 \%, 10$ years: $55 \%$ versus $52 \%$, and 15 years: $51 \%$ versus $45 \%)$ or elective $(30$ days: $95 \%$ versus $98.6 \%$, 1 year: $90 \%$ versus $95 \%, 5$ years: $70 \%$ versus $71 \%$, 10 years: $65 \%$ versus $65 \%$, and 15 years: $60 \%$ versus $61 \%$ ) surgical portocaval shunt [21].

In a study by Perarnau and colleagues, the Kaplan-Meier curve demonstrated that the probability of survival after transjugular intrahepatic portosystemic shunt (TIPS) was not significantly different between patients with and without PVT (1 year: $80 \%$ versus $84 \%, 2$ years: $72 \%$ versus $70 \%$, and 4 years: $55 \%$ versus $52 \% ; P=0.58$, by log-rank test) [22]. Additionally, the median survival time was $50 \pm 12$ months and $36 \pm 5$ months in patients with and without PVT, respectively.

\section{Discussion}

Our study was the first to systematically analyze the effect of PVT on the survival of non-liver-transplant patients with liver cirrhosis. The majority of papers included in our systematic review provided the high-grade evidence. The major findings included the following: (1) PVT might not be significantly associated with the 5-day, 6-week, and 1-year mortality of liver cirrhosis; (2) PVT might be significantly associated with an increased 3-year mortality; (3) PVT might increase the overall mortality during follow-up; and (4) a preexistent PVT did not impact the survival of cirrhotic patients treated with surgical or interventional shunt.

It appears that the short-term survival is not influenced by the presence of PVT. By comparison, the markers of liver dysfunction play a more important role in the prediction of the short-term survival. For example, Amitrano et al. found that Child-Pugh and MELD scores were two significant factors associated with the 5-day mortality [13]; D’Amico and De Franchis also suggested that an increased bilirubin level, a decreased albumin, and encephalopathy predicted a higher 6-week mortality [16]; and Chen et al. reported that MELD score was the independent predictor for the 6-week mortality [15]. Thus, the prognostic value of PVT might be masked by the progressive deterioration of liver function during a relatively short follow-up. In addition, the presence of advanced HCC was often considered the independent predictor for the short-term mortality $[13,15,16]$.

The long-term survival is negatively influenced by the presence of PVT in 4 of 5 studies $[14,18,19,25]$, which indicates the negative impact of PVT on the survival [26]. On the contrary, this is not supported by one study that was published in the abstract form [17]. However, the results of this study should be cautiously interpreted because nearly all decompensation events occurred more frequently in PVT group than in non-PVT group (ascites: $41 \%$ versus $28 \%$; variceal bleeding: 39\% versus 20\%; spontaneous bacterial peritonitis: $23 \%$ versus 9\%; hepatocellular carcinoma: $20 \%$ versus $8 \%$; and portosystemic encephalopathy: $32 \%$ versus $27 \%$ ), but the mortality was relatively lower ( $16 \%$ versus $21 \%$ ) [17].

Villa and colleagues conducted a randomized controlled trial to explore the role of anticoagulation for the primary prevention of PVT in liver cirrhosis [27]. The investigators found that the prophylactic anticoagulation could not only decrease the incidence of PVT, but also reduce the development of hepatic decompensation events and improve the survival. Recently, it has been also proposed that the identification of thrombotic risk factors for PVT should be helpful to stratify the benefits of prophylactic anticoagulation in liver cirrhosis $[28,29]$. However, we have to acknowledge that few thrombotic risk factors for PVT have been clearly established in a small number of patients with liver cirrhosis [30-33]. In addition, anticoagulation could be effective for the treatment of PVT in liver cirrhosis [34-37]. Thus, anticoagulation should be recommended for the management of PVT in liver cirrhosis. Importantly, if a PVT could be avoided in the future or a previously thrombosed portal vein was successfully recanalized, the survival might be further improved.

On the other hand, TIPS is also regarded as a treatment of choice for PVT in liver cirrhosis [38]. Its advantages are that the occluded vessels can be easily recanalized by endovascular techniques, and the patency of vessels can be effectively maintained by an accelerated blood flow through the main portal vein and shunt. However, its primary treatment goal remains to resolve the portal hypertension-related complications [39] because no controlled trials are available to confirm the benefits of TIPS versus anticoagulation for recanalizing the thrombosed portal vein [40]. Despite that, our systematic review showed that the survival of cirrhotic patients who were treated with TIPS or surgical shunts was not influenced by the presence of a preexistent PVT. The indirect evidence suggested that the creation of a portosystemic shunt might improve the survival of liver cirrhosis with PVT.

Our study had several limitations. First, we could not combine the data reported by these included studies into a general result. This was primarily because the ways of data expression and lengths of follow-up were heterogeneous 
among studies. For example, some papers reported the total number of patients and the number of death events; by contrast, the others reported the ORs or HRs. Additionally, some papers just reported the short-term survival; contrarily, the others reported the survival during the total followup. Second, we could not extract the information regarding whether or not the degree of PVT (complete occlusion versus partial occlusion) and Child-Pugh classes (class $C$ versus classes $\mathrm{A} / \mathrm{B}$ ) were able to further stratify the effect of PVT on the survival of liver cirrhosis. Third, some included papers did not exclude the cases with hepatocellular carcinoma. This precluded us from distinguishing whether the nature of PVT was benign or malignant. The presence of malignant PVT was associated with very poor survival. Fourth, although the search strategy was extensive, the number of relevant papers was relatively small. Thus, the reproducibility of these findings remained to be confirmed.

In conclusion, the presence of PVT might be negatively associated with the long-term survival, but not with the shortterm survival, which might support the necessity of anticoagulation or other treatment modalities for maintaining the portal vein patency in liver cirrhosis. Certainly, we should acknowledge that the effect of PVT on the long-term survival after surgical shunt or TIPS was not significant.

\section{Conflict of Interests}

The authors declare that there is no conflict of interests regarding the publication of this paper.

\section{Authors' Contribution}

Xingshun Qi conceived and drafted the paper. Xingshun Qi, Man Yang, Weirong Ren, Jia Jia, and Junna Dai performed the literature search and selection and/or data extraction. Xiaozhong Guo gave critical comments and revised the paper. All authors have made an intellectual contribution to the paper and approved the submission.

\section{References}

[1] E. A. Tsochatzis, J. Bosch, and A. K. Burroughs, "Liver cirrhosis," The Lancet, vol. 383, no. 9930, pp. 1749-1761, 2014.

[2] D. Schuppan and N. H. Afdhal, "Liver cirrhosis," The Lancet, vol. 371, no. 9615, pp. 838-851, 2008.

[3] R. Lozano, M. Naghavi, K. Foreman et al., "Global and regional mortality from 235 causes of death for 20 age groups in 1990 and 2010: a systematic analysis for the Global Burden of Disease Study 2010," The Lancet, vol. 380, pp. 2095-2128, 2012.

[4] C. J. Murray, T. Vos, R. Lozano et al., "Disability-adjusted life years (DALYs) for 291 diseases and injuries in 21 regions, 19902010: a systematic analysis for the Global Burden of Disease Study 2010," The Lancet, vol. 380, no. 9859, pp. 2197-2223, 2012.

[5] G. D’Amico, G. Garcia-Tsao, and L. Pagliaro, "Natural history and prognostic indicators of survival in cirrhosis: a systematic review of 118 studies," Journal of Hepatology, vol. 44, no. 1, pp. 217-231, 2006.

[6] G. Garcia-Tsao, S. Friedman, J. Iredale, and M. Pinzani, "Now there are many (stages) where before there was one: in search of a pathophysiological classification of cirrhosis," Hepatology, vol. 51, no. 4, pp. 1445-1449, 2010.
[7] J. S. Bajaj, J. G. O’Leary, K. R. Reddy et al., "Second infections independently increase mortality in hospitalized patients with cirrhosis: the North American consortium for the study of endstage liver disease (NACSELD) experience," Hepatology, vol. 56, no. 6, pp. 2328-2335, 2012.

[8] V. Arvaniti, G. D’Amico, G. Fede et al., "Infections in patients with cirrhosis increase mortality four-fold and should be used in determining prognosis," Gastroenterology, vol. 139, no. 4, pp. 1246.e5-1256.e5, 2010.

[9] P. S. Kamath and W. R. Kim, "The model for end-stage liver disease (MELD)," Hepatology, vol. 45, no. 3, pp. 797-805, 2007.

[10] X. Qi, G. Han, and D. Fan, "Management of portal vein thrombosis in liver cirrhosis," Nature Reviews Gastroenterology \& Hepatology, vol. 11, no. 7, pp. 435-446, 2014.

[11] X. Qi, M. Yang, W. Ren et al., "Find duplicates among the PubMed, EMBASE, and Cochrane Library Databases in systematic review," PLoS ONE, vol. 8, no. 8, Article ID e71838, 2013.

[12] X. Qi, J. Jia, W. Ren et al., "Scientific publications on portal vein thrombosis and Budd-Chiari syndrome: a global survey of the literature," Journal of Gastrointestinal and Liver Diseases, vol. 23, no. 1, pp. 65-71, 2014.

[13] L. Amitrano, M. A. Guardascione, F. Manguso et al., "The effectiveness of current acute variceal bleed treatments in unselected cirrhotic patients: refining short-term prognosis and risk factors," The American Journal of Gastroenterology, vol. 107, no. 12, pp. 1872-1878, 2012.

[14] A. F. Attili, M. Lupo, F. Gigliotti, S. Trapani, F. Attili, and A. de Santis, "Portal vein thrombosis is a risk factor for death and complications in liver cirrhosis," Digestive and Liver Disease, vol. 44, supplement 2, p. S107, 2012.

[15] P.-H. Chen, W.-C. Chen, M.-C. Hou et al., "Delayed endoscopy increases re-bleeding and mortality in patients with hematemesis and active esophageal variceal bleeding: a cohort study," Journal of Hepatology, vol. 57, no. 6, pp. 1207-1213, 2012.

[16] G. D’Amico and R. De Franchis, "Upper digestive bleeding in cirrhosis. Post-therapeutic outcome and prognostic indicators," Hepatology, vol. 38, no. 3, pp. 599-612, 2003.

[17] M. Doumit, S. Bolano, E. Yeung, K. Khalili, and F. Wong, "The prevalence of non-tumor related portal vein thrombosis," Canadian Journal of Gastroenterology, vol. 23, 2009.

[18] C. N. Ferreira, T. Rodrigues, P. Alexandrino, F. Ramalho, and J. F. Velosa, "Portal vein thrombosis in cirrhotic patients is associated with advanced liver disease and predicts poor longterm prognosis," Hepatology, vol. 52, article 1072A, 2010.

[19] H.-H. Hung, C.-J. Chang, M.-C. Hou et al., "Efficacy of nonselective beta-blockers as adjunct to endoscopic prophylactic treatment for gastric variceal bleeding: a randomized controlled trial," Journal of Hepatology, vol. 56, no. 5, pp. 1025-1032, 2012.

[20] S. W. Lee, T. Y. Lee, C. S. Chang, C. W. Ko, H. Z. Yeh, and S. $\mathrm{S}$. Yang, "Independent factors associated with early outcome in Chinese cirrhotic patients after cessation of initial esophageal variceal hemorrhage," Journal of Clinical Gastroenterology, vol. 44, no. 6, pp. e123-e127, 2010.

[21] M. J. Orloff, M. S. Orloff, S. L. Orloff, and B. Girard, "Portal vein thrombosis in cirrhosis with variceal hemorrhage," Journal of Gastrointestinal Surgery, vol. 1, no. 2, pp. 123-131, 1997.

[22] J.-M. Perarnau, A. Baju, L. D’Aalteroche, J. Viguier, and J. Ayoub, "Feasibility and long-term evolution of TIPS in cirrhotic patients with portal thrombosis," European Journal of Gastroenterology and Hepatology, vol. 22, no. 9, pp. 1093-1098, 2010. 
[23] I. J. Sarfeh, "Portal vein thrombosis associated with cirrhosis: clinical importance," Archives of Surgery, vol. 114, no. 8, pp. 902905, 1979.

[24] R. Windle and J. H. Peacock, "Prognosis after portocaval anastomosis: a 15 year follow up," British Journal of Surgery, vol. 62, no. 9, pp. 701-706, 1975.

[25] C.-Y. Wu, H.-Z. Yeh, and G.-H. Chen, "Pharmacologic efficacy in gastric variceal rebleeding and survival: including multivariate analysis," Journal of Clinical Gastroenterology, vol. 35, no. 2, pp. 127-132, 2002.

[26] X. Qi, M. Bai, Z. Yang et al., "Occlusive portal vein thrombosis as a new marker of decompensated cirrhosis," Medical Hypotheses, vol. 76, no. 4, pp. 522-526, 2011.

[27] E. Villa, C. Cammà, M. Marietta et al., "Enoxaparin prevents portal vein thrombosis and liver decompensation in patients with advanced cirrhosis," Gastroenterology, vol. 143, no. 5, pp. 1253.e4-1260.e4, 2012.

[28] X. Qi, X. Guo, and D. Fan, "Benefit stratification of prophylactic anticoagulation in liver cirrhosis: more questions than answers," Clinical Gastroenterology and Hepatology, 2014.

[29] M. B. Fallon and S. Batra, "Inherited thrombophilia and the risk of portal vein thrombosis: progress toward individualized anticoagulation in cirrhosis?" Clinical Gastroenterology and Hepatology, vol. 12, no. 11, pp. 1813-1814, 2014.

[30] X. Qi, Z. Yang, V. de Stefano, and D. Fan, "Methylenetetrahydrofolate reductase C677T gene mutation and hyperhomocysteinemia in Budd-Chiari syndrome and portal vein thrombosis: a systematic review and meta-analysis of observational studies," Hepatology Research, vol. 44, pp. E480-E498, 2014.

[31] X. Qi, W. Ren, V. De Stefano, and D. Fan, "Associations of coagulation factor V Leiden and prothrombin G20210A mutations with Budd-Chiari syndrome and portal vein thrombosis: a systematic review and meta-analysis," Clinical Gastroenterology and Hepatology, vol. 12, pp. 1801-1812, 2014.

[32] X. Qi, H. Chen, and G. Han, "Effect of antithrombin, protein $\mathrm{c}$ and protein $\mathrm{s}$ on portal vein thrombosis in liver cirrhosis: a meta-analysis," The American Journal of the Medical Sciences, vol. 346, no. 1, pp. 38-44, 2013.

[33] X. Qi, V. de Stefano, C. Su, M. Bai, X. Guo, and D. Fan, "Associations of antiphospholipid antibodies with splanchnic vein thrombosis: a systematic review with meta-analysis," Medicine, vol. 94, no. 4, article e496, 2015.

[34] M. Senzolo, T. M. Sartori, V. Rossetto et al., "Prospective evaluation of anticoagulation and transjugular intrahepatic portosistemic shunt for the management of portal vein thrombosis in cirrhosis," Liver International, vol. 32, no. 6, pp. 919-927, 2012.

[35] M. G. Delgado, S. Seijo, I. Yepes et al., "Efficacy and safety of anticoagulation on patients with cirrhosis and portal vein thrombosis," Clinical Gastroenterology and Hepatology, vol. 10, no. 7, pp. 776-783, 2012.

[36] L. Amitrano, M. A. Guardascione, A. Menchise et al., "Safety and efficacy of anticoagulation therapy with low molecular weight heparin for portal vein thrombosis in patients with liver cirrhosis," Journal of Clinical Gastroenterology, vol. 44, no. 6, pp. 448-451, 2010.

[37] X. Qi, V. de Stefano, H. Li, J. Dai, X. Guo, and D. Fan, "Anticoagulation for the treatment of portal vein thrombosis in liver cirrhosis: a systematic review and meta-analysis of observational studies," European Journal of Internal Medicine, vol. 26, no. 1, pp. 23-29, 2015.
[38] X. Qi and G. Han, "Transjugular intrahepatic portosystemic shunt in the treatment of portal vein thrombosis: a critical review of literature," Hepatology International, vol. 6, no. 3, pp. 576-590, 2012.

[39] T. D. Boyer and Z. J. Haskal, "The role of transjugular intrahepatic portosystemic shunt in the management of portal hypertension," Hepatology, vol. 41, no. 2, pp. 386-400, 2005.

[40] X. Qi, C. He, Z. Yin et al., "Transjugular intrahepatic portosystemic shunt for the prevention of variceal rebleeding in cirrhotic patients with portal vein thrombosis: study protocol for a randomised controlled trial," BMJ Open, vol. 3, no. 7, Article ID e003370, 2013. 


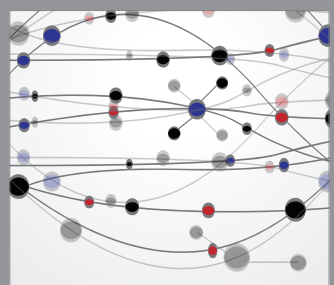

The Scientific World Journal
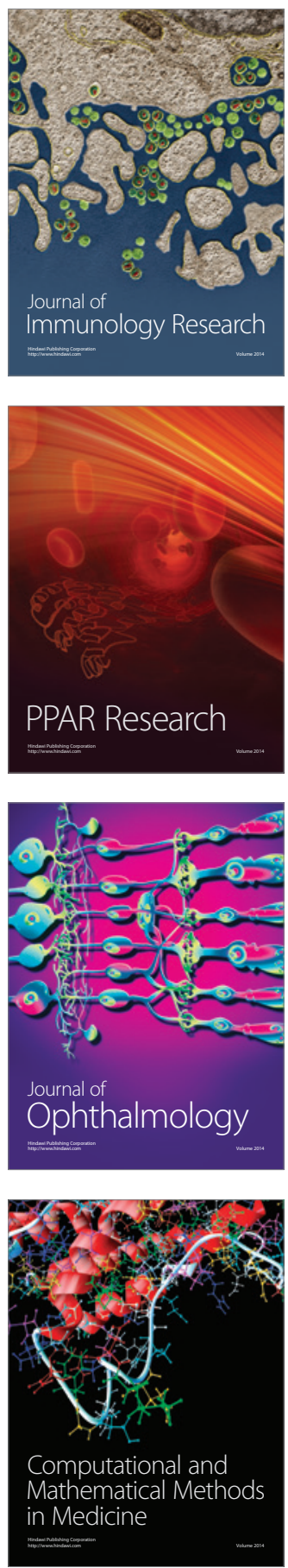

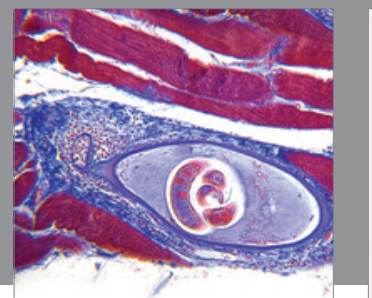

Gastroenterology

Research and Practice
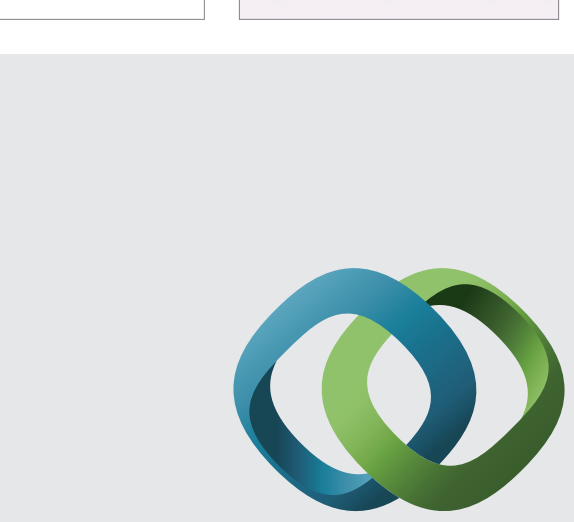

\section{Hindawi}

Submit your manuscripts at

http://www.hindawi.com
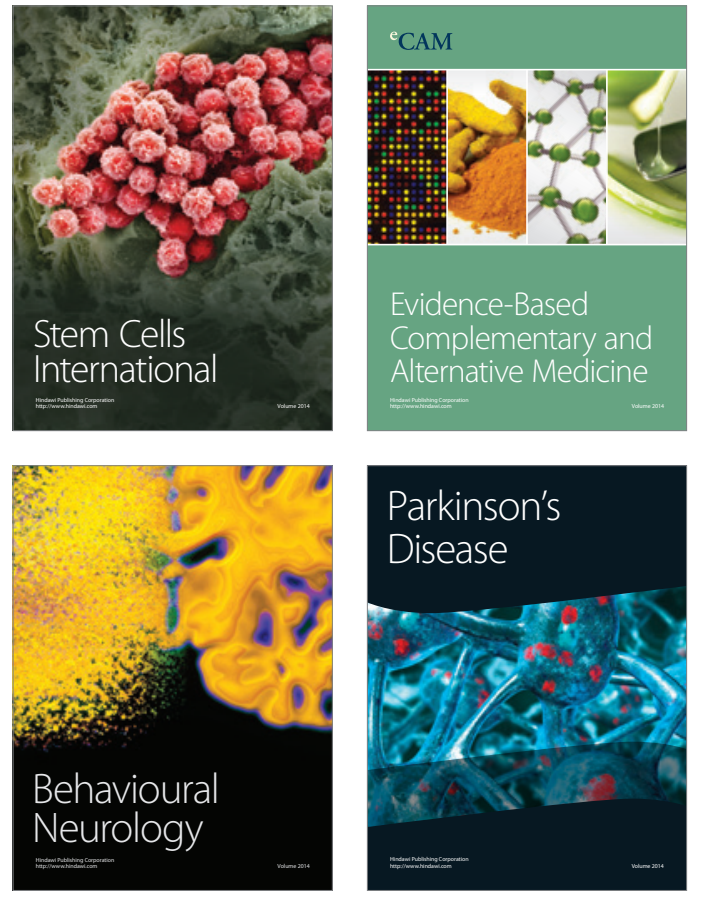
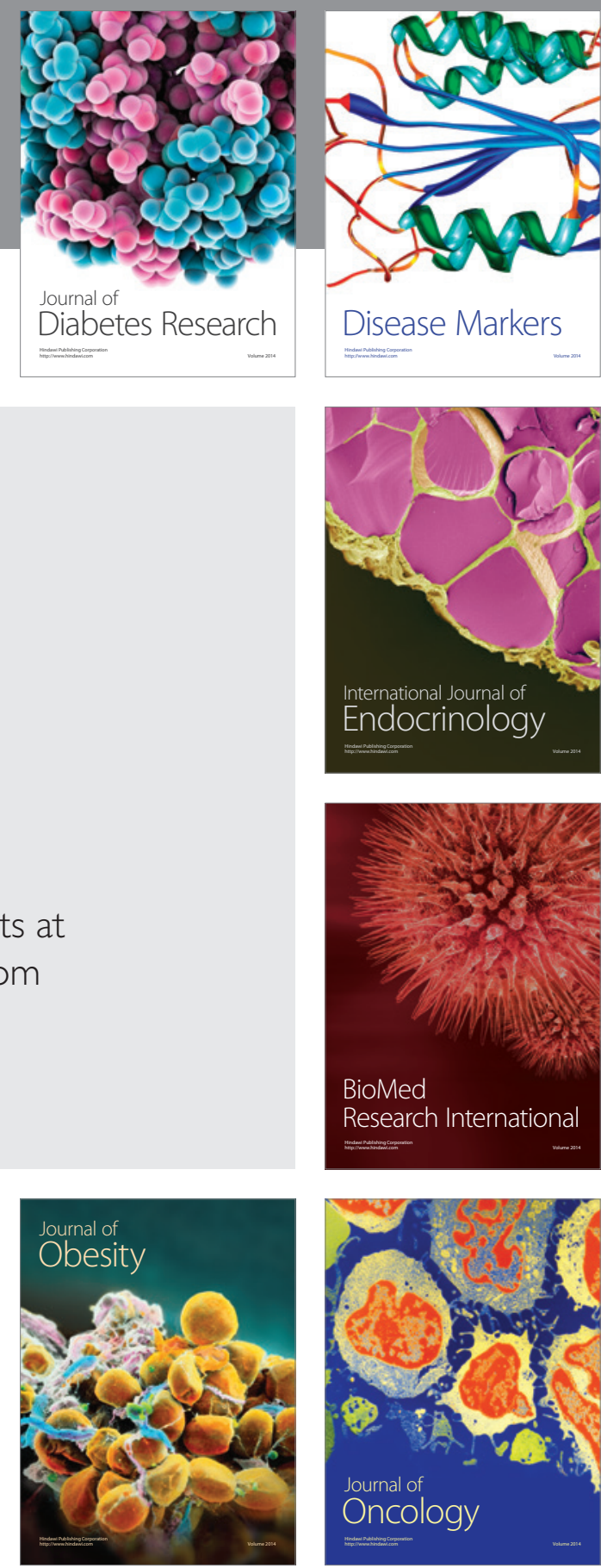

Disease Markers
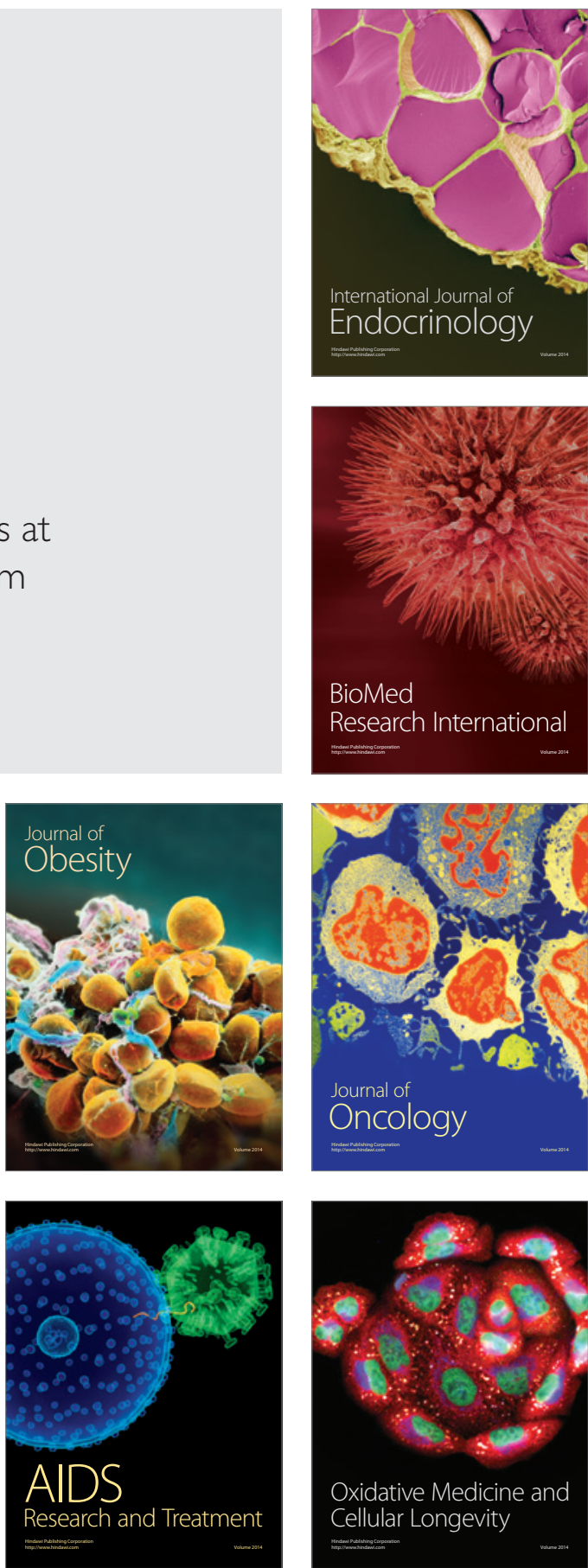